\title{
openheart Prevalence of clOpidogrel 'resIstaNce' in a selected population of patients undergoing elective percutaneous coronary intervention at a tertiary cardiovascular centre in Trinidad: the POINT pilot study
}

\author{
Naveen Anand Seecheran, ${ }^{1}$ Aarti Maharaj, ${ }^{2}$ Brent Boodhai, ${ }^{2}$ Rajeev Seecheran, ${ }^{2}$ \\ Valmiki Seecheran, ${ }^{2}$ Sangeeta Persad, ${ }^{2}$ Koomatie Ramsaroop, ${ }^{2}$ Sherry Sandy, ${ }^{1}$ \\ Stanley Giddings, ${ }^{1}$ Sateesh Sakhamuri, ${ }^{1}$ Ronan Ali, ${ }^{1}$ Shastri Motilal, ${ }^{1}$ \\ Surujpal Teelucksingh, ${ }^{1}$ Antonio Tello-Montoliu ${ }^{3}$
}

To cite: Seecheran NA, Maharaj A, Boodhai B, et al. Prevalence of clOpidogrel 'reslstaNce' in a selected population of patients undergoing elective percutaneous coronary intervention at a tertiary cardiovascular centre in Trinidad: the POINT pilot study. Open Heart 2019;6:e000841. doi:10.1136/

openhrt-2018-000841

Received 19 April 2018 Revised 12 November 2018 Accepted 20 January 2019

Check for updates

(C) Author(s) (or their employer(s)) 2019. Re-use permitted under CC BY-NC. No commercial re-use. See rights and permissions. Published by BMJ.

${ }^{1}$ Clinical Medical Sciences, University of the West Indies at Saint Augustine Faculty of Medical Sciences, Saint Augustine, Trinidad and Tobago ${ }^{2}$ Department of Medicine, North Central Regional Health Authority, Champ Fleurs,

Trinidad and Tobago

${ }^{3}$ Cardiology Unit, Universidad de Murcia, Murcia, Spain

Correspondence to Dr Naveen Anand Seecheran; nseecheran@gmail.com

\section{ABSTRACT}

Objectives This novel, pilot study aimed to assess the estimated prevalence of high on-treatment platelet reactivity (HPR) in Trinidad and Tobago.

Methods Patients $(n=40)$ who were awaiting elective percutaneous coronary intervention on maintenance dual antiplatelet therapy (DAPT) with aspirin $81 \mathrm{mg}$ daily and clopidogrel $75 \mathrm{mg}$ or loaded at least 48 hours prior were recruited. Platelet reactivity with the VerifyNow P2Y12 assay (Accriva Diagnostics, San Diego, California, USA) was assessed prior to cardiac catheterisation.

Results $60.7 \%$ (17/28) of the South Asian (IndoTrinidadians) patients had HPR, whereas 14.3\% (1/7) of Africans and $40 \%(2 / 5)$ of mixed ethnicity had HPR. There was a significant association between HPR (P2Y12 reaction units $>208$ ) and ethnicity with South Asians (IndoTrinidadians) (OR 5.4; 95\% Cl 1.18 to $24.66, \mathrm{p}=0.029$ ). Conclusions This pilot study serves to introduce the preliminary observation that the estimated prevalence of HPR is considerably higher within the heterogeneous population in Trinidad at $50 \%$ as compared with predominantly Caucasian studies. Furthermore, the HPR is significantly higher in South Asians (IndoTrinidadians) ( $>60 \%$ of patients) which has severe clinical repercussions considering the cardiovascular disease pandemic. Clopidogrel may not be a satisfactory or optimal antiplatelet agent in this subgroup, and therefore, another more potent antiplatelet such as ticagrelor should be used instead. Further large-scale studies are imperative to confirm these findings. (Funded by the University of the West Indies, St. Augustine; POINT ClinicalTrials.gov number, NCT03667066.)

\section{INTRODUCTION}

Clopidogrel, a second-generation oral thienopyridine, remains an integral component of dual antiplatelet therapy (DAPT) in

\section{Key questions}

What is already known about this subject?

- Clopidogrel, a second-generation oral thienopyridine, remains an integral component of dual antiplatelet therapy in the management of cardiovascular disease. Several studies underscore the importance of high on-treatment platelet reactivity (HPR) as a prognosticator for cardiovascular events, including stent thrombosis.

- Clopidogrel resistance is a significant clinical entity that has potentially devastating implications including cardiovascular mortality, however has not yet been described in Trinidad, an island with the highest reported prevalence of cardiovascular disease in the Caribbean.

What does this study add?

- This pilot study serves to introduce the preliminary observation that the estimated prevalence of HPR is considerably higher within the heterogeneous population in Trinidad at $50 \%$ as compared with predominantly Caucasian studies based in the USA and Western Europe. Furthermore, the HPR is significantly higher in the subgroup of South Asians (Indo-Trinidadians) ( $>60 \%$ of patients), a population in which there is a long recognised, but incompletely understood very high burden of cardiovascular disease.

How might this impact on clinical practice?

- Clopidogrel may not be a satisfactory or optimal antiplatelet agent in this subgroup, and therefore, another more potent antiplatelet such as ticagrelor should be used instead.

the management of cardiovascular disease (CVD) for almost two decades. Several studies underscore the importance of high on-treatment platelet reactivity $(\mathrm{HPR})$ as a 
prognosticator for cardiovascular events, including stent thrombosis. ${ }^{1-3}$ This phenomenon is often alluded to as 'clopidogrel resistance' and yet to be clearly defined. Generally, it reflects the failure to achieve its antiaggregatory effect. Clopidogrel response is both complex and multifactorial, determined by a multitude of intrinsic and extrinsic mechanisms, including genetic polymorphisms of the P2Y12 receptor, drug-drug interactions, and clinical factors such as suboptimal dosing regimens, acute coronary syndromes (ACS), ${ }^{4}$ diabetes mellitus ${ }^{5}$ and possibly smoking. ${ }^{6}$

High pretreatment platelet reactivity may lead to mitigated clopidogrel-induced antiplatelet effects ${ }^{7-9}$ and are more commonly observed in specific clinical scenarios such as ACS, increased body mass index and diabetes mellitus, in particular, insulin-dependent diabetes mellitus. ${ }^{5} 10$ Matetzky et al also surmised that nearly one-quarter of patients with ST-segment elevation ACS would incur stent thrombosis due to this phenomenon. ${ }^{3}$

Overall, HPR prevalence in various studies is estimated at $5 \%-44 \%^{11}$; however, these are based on largely Caucasian populations and yet to be ascertained in a Caribbean subpopulation. Trinidad and Tobago has an ethnically diverse population with approximately one-third South Asian (Indo-Trinidadian), one-third Caribbean Black (Afro-Trinidadian) and the remaining one-third, mostly interracial and mixed. ${ }^{12-14}$ CVD is currently the leading cause of mortality in Trinidad and Tobago, accounting for up to $60 \%$ of all deaths annually. ${ }^{15}$

The aim of this study was to determine the prevalence of clopidogrel resistance among a selected group of patients undergoing elective percutaneous coronary intervention (PCI) and to observe whether there was any South Asian (Indo-Trinidadian) predilection for HPR considering the well-established epidemiologic trends for accelerated coronary artery disease within this subgroup. ${ }^{16} 17$

\section{MATERIALS AND METHODS}

\section{Study design and patient population}

This is a cross-sectional, open-label (Plavix; Sanofi SA, Gentilly, France and Bristol-Myers Squibb, New York, USA) pilot study aimed to assess HPR which occurred during the period January 2017-September 2017. Patients were screened with a stratified permuted block randomisation technique at the cardiac catheterisation laboratory (cardiac bays 1-4) at our institution (Eric Williams Medical Sciences Complex, Trinidad and Tobago) during assigned recruitment days (Mondays, Tuesdays and Thursdays). The clinical research associates were blinded to the allocation assignment and randomisation sequence numbers were obtained from SPSS V.24.0 software. On average, 1-2 patients were enrolled every week for 8 months. They were considered eligible for the study if they were above 18 years of age and awaiting elective PCI on DAPT for at least 2 weeks with aspirin $81 \mathrm{mg}$ per day maintenance dose and 'brand name' clopidogrel 75 mg per day maintenance dose (Plavix; Sanofi SA and
Bristol-Myers Squibb) or received a loading dose of clopidogrel $600 \mathrm{mg}$ at least 48 hours prior to PCI. Exclusion criteria for this study included generic clopidogrel, that is, not 'brand name', no recent ACS within 6 months, active bleeding, prior cerebrovascular event, clinical instability after an index event, use of an oral anticoagulation agent (coumadin derivative or other anticoagulant therapy (such as dabigatran, rivaroxaban or apixaban)), platelet count $<100 \times 10^{9} / \mathrm{L}$, haemoglobin $<100 \mathrm{~g} / \mathrm{L}$ and serum creatinine $>2.5 \mathrm{mg} / \mathrm{dL}$. The study complied with the Declaration of Helsinki, ${ }^{18}$ International Conference on Harmonization, Good Clinical Practice. ${ }^{19}$ All participants provided written informed consent. Patients were followed up for 14 days postprocedure after completing the study to assess whether they experienced any adverse events.

\section{Blood sampling and VerifyNow P2Y12 testing}

Clopidogrel was held on the morning of their fasting scheduled visit (08:00-09:00) so that their last maintenance dose of clopidogrel was 18-24 hours before baseline blood sampling. This was done to ensure determination of trough levels of platelet reactivity. Blood samples were obtained at rest by antecubital puncture using a 21-gauge needle and placed into Vacuette (Greiner Bio-One North America, Monroe, North Carolina, USA) blood collecting tubes containing $3.8 \%$ trisodium citrate after discarding the first $5 \mathrm{~mL}$ of blood to avoid spontaneous platelet activation. Samples were processed by laboratory personnel blinded to ongoing study data. Platelet function assays included the VerifyNow P2Y12 (VN-P2Y12) assay (Accriva Diagnostics, San Diego, California, USA). The assays were performed according to standard protocols as previously described. ${ }^{2021}$ The VN-P2Y12 assay is a rapid whole blood point-of-care device that reports results as P2Y12 reaction units (PRU). This assay mimics turbidimetric aggregation and utilises disposable cartridges containing $20 \mathrm{mM}$ ADP and $22 \mathrm{nM}$ prostaglandin E1 (PGE1). Aggregation testing using ADP as a sole agonist activates P2Y1 and P2Y12 purinergic signalling, while adding PGE1 increases the specificity of the test for P2Y12 signalling. In a separate channel of the cartridge in which iso-thrombin receptor activating peptide is used as an agonist, a baseline value for platelet function is obtained, enabling assessment of platelet inhibition without having to wean the patient off antiplatelet treatment. The VN-P2Y12 assay reports the results as PRU. A PRU >208 was considered for defining HPR according to the last consensus. ${ }^{1}$

\section{Patient interview and case report form}

The patient's demographic and ${ }^{22}$ anthropometric data were recorded on a case report form and included the patient's medical and procedural history including any active cardiovascular medications. Following this interview, the participant proceeded to cardiac catheterisation for which a SYNTAX score was calculated. ${ }^{23}{ }^{24}$ Echocardiography was also performed as per American College 
of Cardiology, American Heart Association and American Society of Echocardiography guidelines. ${ }^{25}$

\section{Statistical analysis}

Continuous variables were expressed as means $\pm \mathrm{SD}$ and categorical variables as frequencies and percentages. The primary endpoint of PRU using a cut-off of $>208$ for HPR was used to create a dichotomous variable. Unadjusted binary logistic regression models were carried out to explore potential predictors of PRU $>208$. No adjustments for multiple comparisons were made. Missing data were not imputed. The arbitrary, same sample size of 40 was used for the exploratory analyses based on prior studies and in line with recommendations for pilot investigations. ${ }^{232627}$ This was also in keeping with an estimated sample size of 36 patients which was calculated based on a two-sided p-value of 0.05 , power of $80 \%$, estimated baseline prevalence of $20 \%$ of PRU $>208$ and absolute delta of $20 \%$ (expected prevalence of $40 \%$ of PRU >208). A two-tailed p-value of 0.05 was considered to indicate a statistically significant difference for all the analyses performed. Statistical analysis was performed using SPSS V.24.0 software.

\section{RESULTS}

A total of 40 individuals were enrolled in the study. The table 1 shows the demographics of the study participants. The mean age was 56.9 years. Of the patients, almost $60 \%$ were males, with $70 \%$ being South Asian (Indo-Trinidadian) in ethnicity and the remainder Caribbean Black (Afro-Caribbean) and mixed. The mean body mass index was 26.47 . The prevalence of diabetes was $55 \%$, hypertension $70 \%$ and dyslipidaemia $62.5 \%$. Chronic kidney and lung disease, together with cerebrovascular and peripheral artery disease each accounted for less than $5 \%$ comorbidity. Hundred per cent of study participants were on DAPT with aspirin and clopidogrel. There was also a prevalence of at least $80 \%$ for ACE-inhibitors, beta blockers and high-intensity statins; $60.7 \%(17 / 28)$ of the South Asian (Indo-Trinidadians) patients had HPR, whereas $14.3 \%(1 / 7)$ of Africans and $40 \%(2 / 5)$ of mixed ethnicity had HPR. There was a significant association between HPR (PRU > 208) and ethnicity with South Asians (Indo-Trinidadians) (OR 5.4; 95\% CI 1.18 to 24.66, $\mathrm{p}=0.029$ ) (see table 2 ). There were no other significant interactions for HPR and gender, diabetes mellitus, statin therapy, body mass index, ejection fraction and SYNTAX score.

\section{DISCUSSION}

This pilot study reveals a relatively high prevalence of clopidogrel resistance of $50 \%$ which is higher when compared with international studies ${ }^{28}$ and would be unique for the Caribbean setting.

Clopidogrel activation takes place via two sequential oxidation reactions that are catalysed by the cytochrome P450 (CYP450) system, notably involving the CYP2C9 and
Table 1 Patient population

\begin{tabular}{lc}
\hline Characteristics & Frequency (\%) \\
\hline Age & 56.9 (range 43-77) \\
\hline Gender & \\
\hline Female & $17(42.5)$ \\
\hline Male & $23(57.5)$ \\
\hline Ethnicity & \\
\hline South Asian (Indo-Trinidadian) & $28(70)$ \\
\hline Caribbean Black (Afro-Trinidadian) & $7(17.5)$ \\
\hline Mixed/Others & $5(12.5)$ \\
\hline Body mass index & $26.47($ range $18.48-45.7)$ \\
\hline Comorbidities & \\
\hline Diabetes mellitus & $22(55)$ \\
\hline Hypertension & $28(70)$ \\
\hline Dyslipidaemia & $25(62.5)$ \\
\hline Chronic kidney disease & $1(2.5)$ \\
\hline Cerebrovascular events & $2(5.0)$ \\
\hline Chronic obstructive pulmonary disease & $1(2.5)$ \\
\hline Peripheral artery disease & $0(0)$ \\
\hline Cardiovascular medications & \\
\hline Aspirin & $3(7.5)$ \\
\hline Clopidogrel & \\
\hline ACE inhibitor/angiotensin receptor blocker & $35(87.5)$ \\
\hline Beta blocker & $35(87.5)$ \\
\hline Statin & $36(90)$ \\
\hline Calcium channel blocker & $12(30)$ \\
\hline Nitrates & $24(60)$ \\
\hline Trimetazidine & $27(67.5)$ \\
\hline Mineralocorticoid receptor antagonist & $0(0)$ \\
\hline Ivabradine & $0(0)$ \\
\hline Insulin & $12(30)$ \\
\hline Ejection fraction & \\
\hline $25-34$ & $3(7.5)$ \\
\hline $35-45$ & $8(20)$ \\
\hline$>46$ & \\
\hline Platelet reactivity units & \\
\hline$>208$ & $(50.5)$ \\
\hline SYNTAX Score & \\
\hline
\end{tabular}

CYP2C19. A potential contributor to the markedly high HPR in Trinidad could be the similarly high prevalence of the CYP2C19 genotype in the Trinidadian public, specifically the South Asian (Indo-Trinidadians) subpopulation. ${ }^{29}$ Among persons treated with clopidogrel, carriers 
Table 2 Relationship of some comparative variables with respect to high on treatment platelet reactivity (P2Y12 reaction units $>208$ )

\begin{tabular}{llll}
\hline Comparison variables & OR & Cls (95\%) & P value \\
\hline $\begin{array}{l}\text { Male versus female* } \\
\begin{array}{l}\text { South Asian (Indo-Trinidadians) } \\
\text { versus non-South Asian (Caribbean }\end{array}\end{array}$ & 0.97 & 0.28 to 3.40 & 0.962 \\
$\begin{array}{l}\text { Blacks/Afro-Trinidadians, mixed/ } \\
\text { others) }\end{array}$ & & 1.18 to 24.66 & 0.029 \\
$\begin{array}{l}\text { Diabetes mellitus (DM) versus non- } \\
\text { DM* }\end{array}$ & 1.81 & 0.51 to 6.36 & 0.358 \\
$\begin{array}{l}\text { Statin therapy versus no statin } \\
\text { therapy* }\end{array}$ & 0.33 & 0.03 to 3.51 & 0.361 \\
\hline $\begin{array}{l}\text { Body mass index } \\
\text { Ejection fraction (EF) <50\% versus }\end{array}$ & 1.15 & 0.30 to 4.47 & 0.836 \\
EF $>50 \%{ }^{*}$ & 0.98 & 0.88 to 1.10 & 0.770 \\
\hline \begin{tabular}{l} 
SYNTAX score $>33$ versus <33* \\
\hline
\end{tabular} & 3.4 & 0.59 to 19.46 & 0.169 \\
\hline
\end{tabular}

${ }^{*}$ Comparison group.

of a reduced-function CYP2C19 allele had comparatively decreased levels of the active metabolite, attenuated platelet inhibition and a higher rate of major adverse cardiovascular events than did non-carriers. ${ }^{2} 30$ The clinical relevance of clopidogrel response variability is a double-edged sword as there is a delicate balance of the spectrum with a higher ischaemic risk for atherothrombotic events in hyporesponders versus higher bleeding risk in hyper-responders. Additionally, due to its widespread application for both vascular disease and post-cardiovascular interventions, resistance to this agent presents a dilemma in patients with atherothrombotic diseases. ${ }^{31}$ In Trinidad, there was a high proportion $(37 \%)$ of allelic frequencies for CYP2C19*2 in South Asians (Indo-Trinidadian) than Caribbean Black (Afro-Trinidadian) or persons of mixed descent. ${ }^{29}$ The pharmacogenetics of clopidogrel metabolism display marked ethnic variegation. $^{32} 33$ The frequency of CYP2C19*2 mutant alleles in South Asians was higher than in Chinese and Caucasians and as a result of this poor metaboliser genotype frequency of $12.6 \%$, this translates to at least 28 million being poor metabolisers of CYP2C19 substrates in the southern subcontinent alone. ${ }^{34}$ Several other east and southeast Asian studies also demonstrate a similar polymorphism propensity. ${ }^{36-38}$ These patients displayed biochemical characteristics consistent with higher residual platelet reactivity with an attenuated antiplatelet response. The higher prevalence of these CYP2C19 lossof-function alleles may well contribute to worse cardiovascular outcomes in the Asian population as compared with the Western population as evidenced a recent meta-analysis. ${ }^{39}$ The South Asian (Indo-Trinidadians) diaspora in Trinidad as of the national census in 2011 is approximately one-half million persons and with an alarming adult cardiovascular mortality of up to $60 \%,{ }^{15}$ this higher frequency genotype would undoubtedly phenotypically translate as an important practical aspect of management.
As a result, there have been concerns regarding the clinical efficacy and safety of antiplatelet strategies in various ethnicities.

Diabetes is also associated with heightened platelet reactivity and attributed to a complex interplay of factors including hyperglycaemia, hyperlipidaemia, both relative and absolute insulin resistance, oxidative stress, inflammation and endothelial dysfunction. ${ }^{5}$

According to the WHO and International Diabetes Federation, Trinidad has a particularly high burden of diabetes with an estimated prevalence of $13 \%$ and ranks 37th and 10th worldwide and the America, respectively. ${ }^{40}$ This alarming diabetic pandemic can also be implicated in HPR, as the two conditions are mechanistically linked.

As the South Asian (Indo-Trinidadians) subpopulation appears to be replete with HPR, further large-scale studies are imperative to affirm these findings and as such, alternative antithrombotic regimens should be considered on the basis of one's ethnicity. Novel strategies have and are currently being investigated in the ATLAS-ACS 2-TIMI $51,{ }^{42}$ GEMINI-ACS $1,{ }^{43}$ PIONEER AF-PCI trials ${ }^{44}$ among many others.

\section{Study limitations}

The major limitation is that the study is of a pilot design. ${ }^{45}$ As aforementioned, this novel study's objective was to provide preliminary, exploratory observations of clopidogrel 'resistance' in Trinidad which would serve to generate hypotheses for future studies. The sample size was calculated based on speculative data; as this prevalence has not been previously described in this particular setting. It was also in keeping with the guidelines and recommendations of pilot studies, thus enrolling 40 arbitrary, randomised participants. Selection bias can be a potential issue, as all patients were screened at the cardiac catheterisation laboratory and were awaiting PCI and thus, may have an inherent predilection for HPR, although attempts were made to mitigate this by randomising enrolment and stringent selection criteria. Another limitation is that assessing platelet reactivity has many pitfalls including both interindividual and intraindividual variability being affected by smoking, alcohol, fasting and intrinsic circadian rhythms. ${ }^{46-48}$ Generally, the inconsistent VerifyNow P2Y12 point-of-care assay results may complicate management decisions as reactivity is not a stable phenomenon and may require repetitive testing to ascertain 'clopidogrel resistance' status. ${ }^{49}$ Another drawback is that genotyping for these polymorphisms was not performed in this cohort. As a result, we are unable to ascertain the precise relationship between HPR and allelic frequencies for CYP2C19*2, although this was reported previously without evaluating clinical clopidogrel resistance. $^{29}$

\section{CONCLUSIONS}

Clopidogrel resistance is a significant clinical entity that has potentially devastating implications including 
cardiovascular mortality, however has not yet been described in the Caribbean setting. This pilot study serves to introduce the preliminary observation that the estimated prevalence of HPR is considerably higher within the heterogeneous population in Trinidad at 50\% as compared with predominantly Caucasian studies. Furthermore, the HPR is significantly higher in South Asians (Indo-Trinidadians) ( $>60 \%$ of patients) which has severe clinical repercussions considering the cardiovascular disease pandemic. Further large-scale studies are imperative to confirm these findings. Point-of-care testing may be important consideration in high-risk groups such as the South Asian ethnicity (Indo-Trinidadians) and they may require, individualised antithrombotic regimens post-PCI, post-coronary artery bypass grafting and management of ACSs. ${ }^{50}{ }^{51}$ Clopidogrel may not be a satisfactory or optimal antiplatelet agent in this subgroup, and therefore, another more potent antiplatelet such as ticagrelor should be used instead.

Contributors All authors contributed equally in writing the manuscript. All authors read and approved the final manuscript.

Funding Campus Research and Publication Fund (CRP.4MAR16.38) from the University of the West Indies, St. Augustine in the amount of \$50,000 TTD.

Competing interests None declared.

Patient consent for publication Obtained.

Ethics approval All procedures performed in studies involving human participants were in accordance with the ethical standards of the institutional and/or national research committee (Research Ethics Committee of the University of the West Indies, St. Augustine, Trinidad) and with the 1964 Helsinki declaration and its later amendments or comparable ethical standards.

Provenance and peer review Not commissioned; externally peer reviewed.

Data sharing statement All materials, data, code and associated protocols will be made promptly available to the editor and/or readers upon request. If requested, there will not be any restrictions on the availability of materials.

Open access This is an open access article distributed in accordance with the Creative Commons Attribution Non Commercial (CC BY-NC 4.0) license, which permits others to distribute, remix, adapt, build upon this work non-commercially, and license their derivative works on different terms, provided the original work is properly cited, appropriate credit is given, any changes made indicated, and the use is non-commercial. See: http://creativecommons.org/licenses/by-nc/4.0/.

\section{REFERENCES}

1. Tantry US, Bonello L, Aradi D, et al. Consensus and update on the definition of on-treatment platelet reactivity to adenosine diphosphate associated with ischemia and bleeding. J Am Coll Cardiol 2013;62:2261-73.

2. Mega JL, Close SL, Wiviott SD, et al. Cytochrome P-450 polymorphisms and response to clopidogrel. N Engl J Med 2009;360:354-62.

3. Matetzky S, Shenkman B, Guetta V, et al. Clopidogrel resistance is associated with increased risk of recurrent atherothrombotic events in patients with acute myocardial infarction. Circulation 2004;109.

4. Ahn SG, Lee SH, Yoon JH, et al. Different prognostic significance of high on-treatment platelet reactivity as assessed by the VerifyNow P2Y12 assay after coronary stenting in patients with and without acute myocardial infarction. JACC Cardiovasc Interv 2012;5:259-67.

5. Schneider DJ. Factors contributing to increased platelet reactivity in people with diabetes. Diabetes Care 2009;32:525-7.

6. Nguyen TA, Diodati JG, Pharand C. Resistance to clopidogrel: a review of the evidence. J Am Coll Cardiol 2005;45:1157-64.

7. Gurbel PA, Bliden KP, Hiatt BL, et al. Clopidogrel for coronary stenting: response variability, drug resistance, and the effect of pretreatment platelet reactivity. Circulation 2003;107:2908-13.

8. Müller I, Besta F, Schulz C, et al. Prevalence of clopidogrel non-responders among patients with stable angina pectoris scheduled for elective coronary stent placement. Thromb Haemost 2003;89:783-7.

9. Angiolillo DJ, Fernandez-Ortiz A, Bernardo E, et al. Identification of low responders to a 300-mg clopidogrel loading dose in patients undergoing coronary stenting. Thromb Res 2005;115:101-8.

10. Angiolillo DJ, Fernandez-Ortiz A, Bernardo E, et al. Platelet function profiles in patients with type 2 diabetes and coronary artery disease on combined aspirin and clopidogrel treatment. Diabetes 2005;54:2430-5.

11. Gurbel PA, Tantry US. Clopidogrel resistance? Thromb Res 2007;120:311-21.

12. Agency Cl. The CIA World Factbook 2016. Skyhorse Publishing, Inc 2015: 976.

13. Seecheran N, Baldeo S, Balbosa K, et al. Epidemiologic insight into Trinidad's awareness and prevention of heart disease. The EPITAPH study - a trinidadian cardiovascular health literacy survey. Int $J$ Community Med Public Health 2017;4.

14. CSO. Publications \& Documents. Available: http://cso.gov.tt/media/ publications-documents/ [Accessed 15 Feb 2018].

15. PAHO Health in the Americas. PAHO Health in the Americas Website. Available: http://www.paho.org/saludenlasamericas/index.php? option=com_docman\&task=doc_view\&gid=149\&It emid [Accessed 30 Jan 2018]

16. Beckles GLA, Kirkwood BR, Carson DC, et al. High total and cardiovascular disease mortality in adults of Indian descent in Trinidad, unexplained by major coronary risk factors. The Lancet 1986;327:1298-301.

17. Miller GJ, Cooper JA, Beckles GL. Cardiorespiratory fitness, allcause mortality, and risk of cardiovascular disease in Trinidadian men--the St James survey. Int J Epidemiol 2005;34:1387-94.

18. Christie B. Doctors revise Declaration of Helsinki. BMJ 2000;321:913.

19. Wiley Encyclopedia of Clinical Trials, 2008. International Conference on harmonisation of technical requirements for registration of pharmaceuticals for human use (ICH). Available: http://dx.doi.org/10. 1002/9780471462422.eoct457

20. Angiolillo DJ, Badimon JJ, Saucedo JF, et al. A pharmacodynamic comparison of prasugrel vs. high-dose clopidogrel in patients with type 2 diabetes mellitus and coronary artery disease: results of the Optimizing anti-Platelet Therapy In diabetes MellitUS (OPTIMUS)-3 Trial. Eur Heart J 2011;32:838-46.

21. Angiolillo DJ, Saucedo JF, Deraad R, et al. Increased platelet inhibition after switching from maintenance clopidogrel to prasugrel in patients with acute coronary syndromes: results of the swap (switching anti platelet) study. J Am Coll Cardiol 2010;56:1017-23.

22. Collection of race and ethnicity data in clinical trials guidance for industry and food and drug administration staff. Available: https:// www.fda.gov/downloads/Regulatorylnformation/Guidances/ ucm126396.pdf [Accessed 23 Jan 2018].

23. Teare MD, Dimairo M, Shephard N, et al. Sample size requirements to estimate key design parameters from external pilot randomised controlled trials: a simulation study. Trials 2014;15.

24. Kappetein AP, Dawkins KD, Mohr FW, et al. Current percutaneous coronary intervention and coronary artery bypass grafting practices for three-vessel and left main coronary artery disease. Insights from the SYNTAX run-in phase. Eur J Cardiothorac Surg 2006;29:486-91.

25. Cheitlin MD, Armstrong WF, Aurigemma GP, et al. ACC/AHA ASE 2003 guideline update for the clinical application of echocardiography: summary article: a report of the American College of Cardiology/American Heart Association Task Force on practice guidelines (ACC/AHA/ASE Committee to update the 1997 guidelines for the clinical application of echocardiography). Circulation 2003:108:1146-62.

26. Viechtbauer W, Smits L, Kotz D, et al. A Simple formula for the calculation of sample size in pilot studies. J Clin Epidemiol 2015;68:1375-9.

27. Whitehead AL, Julious SA, Cooper CL, et al. Estimating the sample size for a pilot randomised trial to minimise the overall trial sample size for the external pilot and main trial for a continuous outcome variable. Stat Methods Med Res 2016;25:1057-73.

28. Cuisset T, Cayla G, Silvain J. Clopidogrel resistance: what's new? Arch Cardiovasc Dis 2010;103:349-53.

29. Mungrue K, Wyke M, Ramkissoon V, et al. The distribution of altered forms of CYP2C19*2 allele in a Trinidadian population. is clopidogrel the right choice? Eur J Bio Pharm Sci;3:31-6.

30. Mega JL, Simon T, Collet JP, et al. Reduced-function CYP2C19 genotype and risk of adverse clinical outcomes among patients treated with clopidogrel predominantly for $\mathrm{PCl}$ : a meta-analysis. JAMA 2010;304:1821-30. 
31. Uchiyama S. Clopidogrel resistance: identifying and overcoming a barrier to effective antiplatelet treatment. Cardiovasc Ther 2011;29:e100-11.

32. Subraja K, Dkhar SA, Priyadharsini R, et al. Genetic polymorphisms of CYP2C19 influences the response to clopidogrel in ischemic heart disease patients in the South Indian Tamilian population. Eur J Clin Pharmacol 2013;69:415-22.

33. Chan MY. Clopidogrel pharmacogenetics of East, South and other Asian populations. Eur Heart J Supp 2012;14(suppl A):A41-A42.

34. Jose R, Chandrasekaran A, Sam SS, et al. CYP2C9 and CYP2C19 genetic polymorphisms: frequencies in the South Indian population. Fundam Clin Pharmacol 2005;19:101-5.

35. Adithan C, Gerard N, Vasu S, et al. Allele and genotype frequency of CYP2C19 in a Tamilian population. Br J Clin Pharmacol 2003:56:331-3.

36. Levine GN, Jeong YH, Goto S, et al. World heart Federation expert consensus statement on antiplatelet therapy in East Asian patients with ACS or undergoing PCI. Glob Heart 2014;9:457-67.

37. Jeong $\mathrm{Y}-\mathrm{H}$. "East asian paradox": challenge for the current antiplatelet strategy of "one-guideline-fits-all races" in acute coronary syndrome. Curr Cardiol Rep 2014;16.

38. Kim IS, Choi BR, Jeong YH, et al. The CYP2C19*2 and CYP2C19*3 polymorphisms are associated with high post-treatment platelet reactivity in Asian patients with acute coronary syndrome. J Thromb Haemost 2009;7:897-9.

39. Sorich MJ, Rowland A, McKinnon RA, et al. CYP2C19 genotype has a greater effect on adverse cardiovascular outcomes following percutaneous coronary intervention and in Asian populations treated with clopidogrel: a meta-analysis. Circ Cardiovasc Genet 2014;7:895-902.

40. The World Health Organization. Facts and figures about diabetes: country and regional data, 2014. Available: http://www.who.int/ diabetes/facts/world_figures/en/index3.html

41. Yisahak SF, Beagley J, Hambleton IR, et al. Diabetes in North America and the Caribbean: an update. Diabetes Res Clin Pract 2014;103:223-30.
42. Mega JL, Braunwald E, Wiviott SD, et al. Rivaroxaban in patients with a recent acute coronary syndrome. $N$ Engl J Med 2012;366:9-19.

43. Ohman EM, Roe MT, Steg PG, et al. Clinically significant bleeding with low-dose rivaroxaban versus aspirin, in addition to P2Y12 inhibition, in acute coronary syndromes (GEMINIACS-1): a double-blind, multicentre, randomised trial. The Lancet 2017;389:1799-808.

44. Gibson CM, Mehran R, Bode C, et al. Prevention of bleeding in patients with atrial fibrillation undergoing $\mathrm{PCl}$. $N$ Engl J Med 2016;375:2423-34.

45. Lancaster GA, Dodd S, Williamson PR. Design and analysis of pilot studies: recommendations for good practice. J Eval Clin Pract 2004;10:307-12

46. Arméro S, Camoin Jau L, Omar Aït Mokhtar O, et al. Intraindividual variability in clopidogrel responsiveness in coronary artery disease patients under long term therapy. Platelets 2010;21:503-7.

47. Bidet $A$, Jais $C$, Puymirat E, et al. VerifyNow and VASP phosphorylation assays give similar results for patients receiving clopidogrel, but they do not always correlate with platelet aggregation. Platelets 2010;21:94-100.

48. Peace AJ, Egan K, Kavanagh GF, et al. Reducing intra-individual variation in platelet aggregation: implications for platelet function testing. J Thromb Haemost 2009;7:1941-3.

49. Ahn SG, Lee SH, Sung JK, et al. Intra-individual variability of residual platelet reactivity assessed by the VerifyNow-P2Y12 assay in patients with clopidogrel resistance after percutaneous coronary intervention. Platelets 2011;22:305-7.

50. Alfonso F, Angiolillo DJ. Platelet function assessment to predict outcomes after coronary interventions: hype or hope? J Am Coll Cardiol 2006;48:1751-4

51. Rohla M, Weiss TW, Wojta J, et al. Double or triple antithrombotic combination therapy in patients who need anticoagulation and antiplatelet therapy in parallel. Eur Heart $J$ Cardiovasc Pharmacother $2015 ; 1: 191-7$ 